\title{
Flood modelling of upper Gurara watershed using remote sensing data and the geospatial streamflow model
}

\author{
O. A. Agunbiade \& O. D. Jimoh \\ Department of Civil Engineering, Federal University of Technology, \\ Minna, Nigeria
}

\begin{abstract}
This study evaluates the use of Remote Sensing (RS) and Geographic Information System (GIS) technologies to augment the conventional methods used in watershed-scale hydrological modelling and rainfall-runoff studies in the Upper Gurara watershed in Northern Nigeria. Streamflow at the catchment outlet was simulated within a GIS environment at a daily time-step from the year 2001 to 2010, using freely available RS datasets and a physically based, semidistributed hydrological model (GeoSFM). Two procedures were available in the model for estimation of the contribution of soil moisture to streamflow generation: the Nonlinear Soil Moisture Accounting (NSMA), and the Linear Soil Moisture Accounting (LSMA) routines. Model performance was evaluated by comparing the monthly averaged simulated flows with the available observed historical data for 19 years (1971-1989). It was observed that both methods adequately estimated the peak flow occurrence and value when compared with the historically observed data. The log-transformed coefficient of determination $\left(\mathrm{R}^{2}\right)$ between the observed and simulated flow was 0.96 and 0.68 for NSMA and LSMA respectively. It was concluded that the model and datasets performed satisfactorily in simulating the peak discharge in the basin but was inadequate in simulating the rising limb of the hydrograph and the total volume of flow at the catchment outlet.

Keywords: flood modelling, remote sensing, geographic information system, ungauged catchment, soil moisture accounting, data scarce locations.
\end{abstract}




\section{Introduction}

In situ gauging has served as the primary method for operational monitoring of streamflow conditions and for obtaining data required for managing water resources and hazards posed by extreme hydrologic events. The past two decades have however witnessed a serious decline in hydro-meteorological gauging infrastructure in Nigeria due to the huge costs involved in acquisition, monitoring and maintenance of observation gauges. The most abundant data is mainly daily rainfall and to a lesser extent streamflow. Other meteorological data such as temperature, humidity, wind speed, and evaporation are available at daily time step. It is difficult to find data at smaller resolution such as hourly.

As a result of sparse hydrological data, there is a need to explore the option of synthesizing available data and catchment characteristics using modelling system that relies on the physical characteristics of the watershed (topography, soil, landuse and landcover) and satellite-derived weather estimates (rainfall and evapotranspiration). This study seeks to harness the current technological trend in data acquisition and processing to parameterize a physically-based, watershedscale hydrologic model for streamflow simulation in a sparse hydrological data environment. High flows resulting in flooding were experienced in many rivers in 2012 in the country. Many lives were lost and over 2 million peoples were displaced. Agricultural land and crops were also destroyed. The results for this study would facilitate the management of such high flow in Nigeria.

\section{Materials and methods}

\subsection{Study area}

The Gurara river basin is situated in Northern Nigeria, between latitudes $8^{\circ} 15^{\prime}$ and $10^{\circ} 05^{\prime} \mathrm{N}$ and longitudes $6^{\circ} 30^{\prime}$ and $8^{\circ} 30^{\prime} \mathrm{E}$ (Fig. 1). It has a total catchment area of $14,913 \mathrm{~km}^{2}$ at the confluence with river Niger [1]. The Upper Gurara watershed has an area of $4,693 \mathrm{~km}^{2}$ at Jere. The Gurara River extends over a distance of $570 \mathrm{~km}$ from the plateau at an elevation of over $700 \mathrm{~m}$, through Jere at $530 \mathrm{~m}$ and into the Niger confluence at an elevation of $40 \mathrm{~m}$. The Gurara River flows in a general direction of northeast to southwest in its upper reaches, and then turns southwards as it flows through FCT to its confluence with the Niger River [2]. The climate is influenced by the seasonal movement of the Intertropical Convergence Zone (ITCZ), which results in two distinct wet and dry seasons

The basin lies in the southern Guinea Savannah zone of Nigeria and its vegetation type is basically savannah grassland interspersed with remnants of tropical forest. The watercourses are particularly forested with large trees from the fringing forests, with a few patches of typical natural forest reserves. The terrain is undulating and dissected, conforming to the dominant geological structure of the underlying rocks-undifferentiated basement complex. The soil type is generally gravely red laterites, and in the river valleys it is alluvial [3]. 


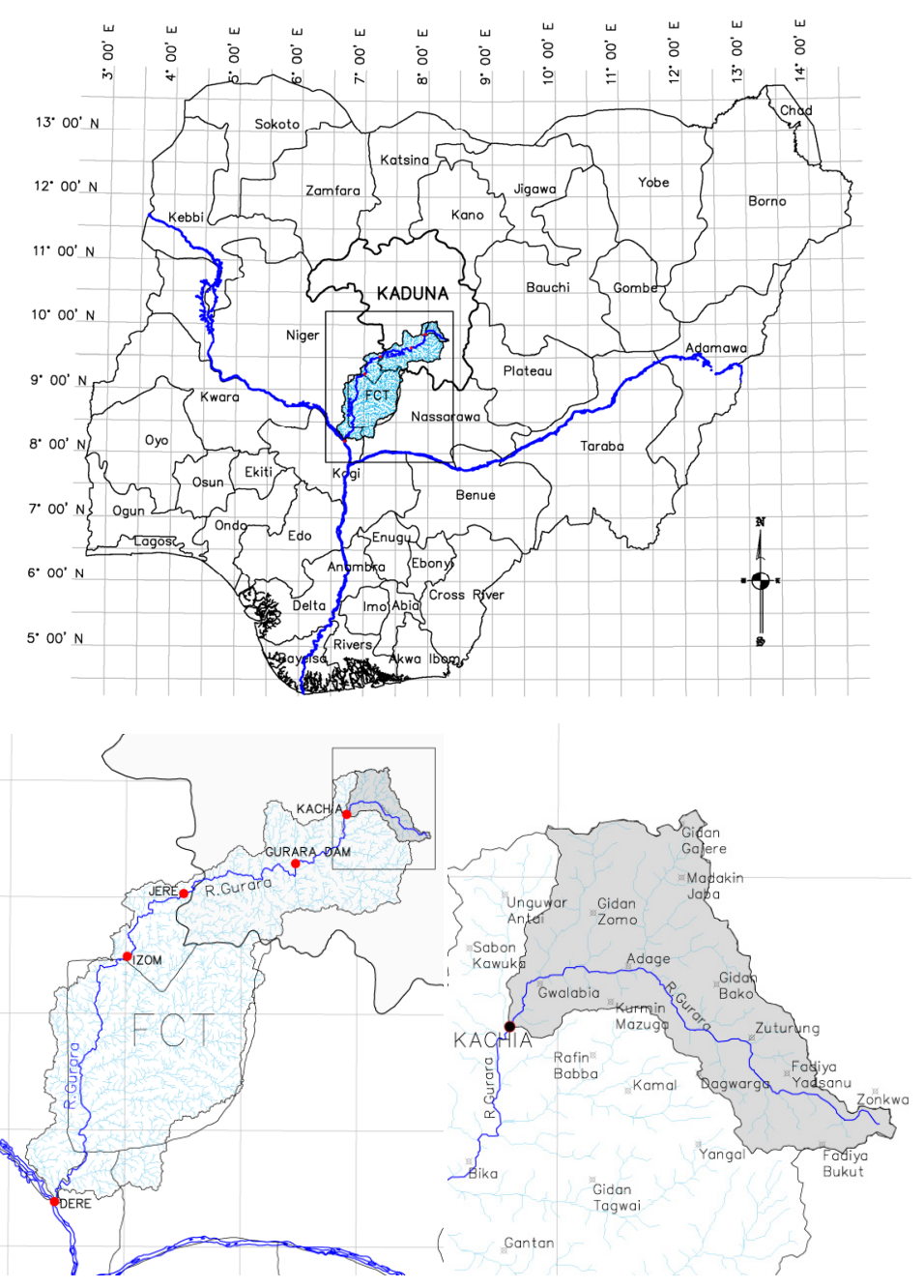

Figure 1: $\quad$ Location of Upper Gurara Watershed.

\subsection{Model structure}

The Geospatial Stream Flow Model (GeoSFM) is a semi-distributed, physically based, catchment-scale, hydrologic modelling system developed by scientists at the United States Geological Survey Centre for Earth Resources Observation and Science (USGS/EROS), with the cooperation of the United States Agency for International Development, Office of Foreign Disaster Assistance [4, 5].

GeoSFM runs within a proprietary GIS environment (ESRI ArcView) for data input, preparation, and visualization of simulation outputs. The general model structure (Fig. 2) involves a preprocessing module used for receiving and 


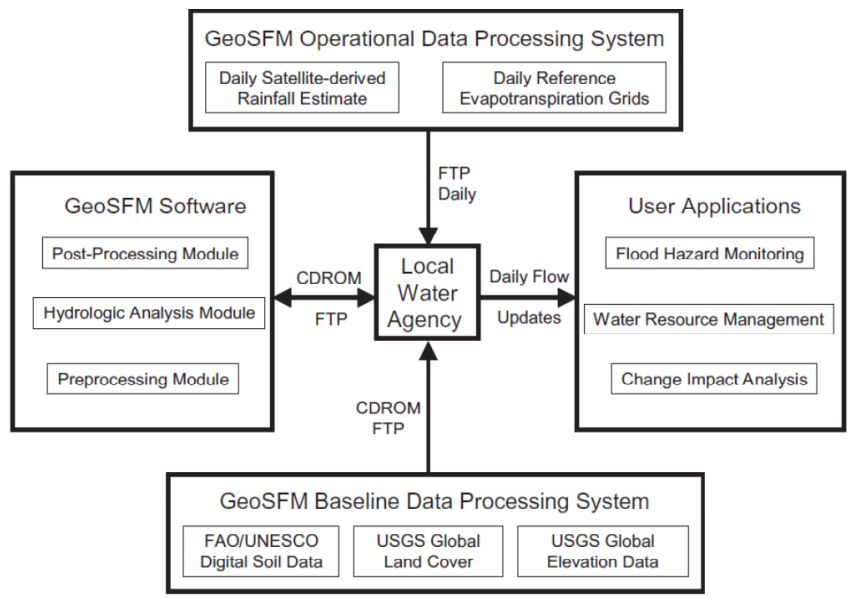

Figure 2: $\quad$ GeoSFM components overview (Source: [8]).

manipulating the input data. Next is the hydrologic analysis module, which consists of a linear soil moisture accounting (LSMA) routine, a more complex nonlinear soil moisture accounting (NSMA) routine, and a choice of three river flow transport routines, namely pure lag, diffusion analogue, and MuskingumCunge. A calibration module is also included, which links the hydrologic analysis routines to a sensitivity analysis routine and a Multi-Objective Shuffled Complex Evolution Metropolis algorithm for parameter calibration [5]. Finally, a post-processing module, which contains various routines for analysing and presenting model output in visual formats, is also included. The good predictions obtained from the GeoSFM model in previous studies [5, 6] and the correspondence between the scientific basis of the GeoSFM model and the actual hydrological processes [7] favour the use of GeoSFM.

\subsection{Input datasets}

The main reason for selecting GeoSFM is the relative ease with which the input data can be acquired for initial parameterization. The digitized or remote sensing datasets are freely available, of global coverage, and can be sourced from the different agencies via the Internet thereby allowing GeoSFM users to undertake basic hydrologic assessments in locations with limited in-situ information.

Soil Characteristics, including soil type, texture and hydraulic conductivity (Ks) values were determined using the Zobler data set [9]. For soil depth characterization, Webb et al. [10] was used. This data set specifies the top and bottom depths and the percentage of the texture type (sand, silt, and clay) of soil horizons. The soil water-holding capacity (WHC) which is the amount of water that the soil can hold, measured in mm, is available at two depths of soil (0-30 and $30-100 \mathrm{~cm}$ ) and were estimated from Reynolds et al. [11]. Landuse and Landcover were based on the USGS Global Land Cover Characterization 
(GLCC) database. The GLCC data set is derived from 1-km Advanced Very High Resolution Radiometer data [12].

Topography/DEM: The Shuttle Radar Topography Mission (SRTM) is a collaborative mission to generate a near-global digital elevation model (DEM) of the Earth using radar interferometry technique. Gathered in February 2000, the SRTM data has a vertical accuracy specification of $+/-5$ meters and is available in resolutions of 1 arc-second (30m) data in the United States and 3 arc-second (90m) data around the world [13]. After importing the DEM into the ArcView GIS environment, the terrain analysis module was then used to generate the subbasins and rivers/stream network within the catchment. This process usually involves the creation of raster data grids necessary for the software to delineate the streams and basins, also a threshold value has to be specified to determine the density of the stream network and size of the sub-basins.

Maximum impervious area accounts for the area covered by a wetland, lake or stream (expressed as a percentage). It was derived from a combination of the landuse/landcover data and areas designated as stream channels from the DEM analysis with procedures performed within the ArcView GIS environment.

The Soil Conservation Service (SCS) method was used to determine the amount of incident precipitation that becomes surface runoff. The runoff curve number was estimated from landuse and landcover data and hydraulic soil classes.

Rainfall data is the most essential input to any hydrologic model. The primary rainfall data used for daily simulations in GeoSFM are satellite-derived rainfall estimates produced by the Climate Prediction Centre of the National Oceanic and Atmospheric Administration [14]. Appropriate routine of the model was used to determine the average areal rainfall for each sub-basin and export them to text files for subsequent model use.

Another important model input is the daily potential evapotranspiration (PET) data produced by the Famine Early Warning Systems Network (FEWSNET) [15]. GeoSFM contains procedures for ingesting the resulting PET grids and computing actual daily evapotranspiration based on antecedent soil moisture conditions. Appropriate routine of the model was used to determine the average areal evapotranspiration for each sub-basin and export them to text files for subsequent model use.

\subsection{Model evaluation and sensitivity analysis}

GeoSFM has a well-documented User Manual [16] to assist in setting up, parameterizing and running the model. After acquisition of all the necessary datasets, preprocessing work was done in the native ArcView GIS environment. Ten years (2001 - 2010) of daily satellite-observed precipitation and evapotranspiration data were available for simulation purposes. The model was run on a daily time-step using all permutations of the soil moisture accounting (LSMA and NSMA) and river flow transport (pure lag, diffusion analogue and Muskingum-Cunge) routines to facilitate comparison of their relative effects on streamflow generation. It was discovered that both linear routines (pure lag and diffusion analogue) basically gave the same results and had higher discharge 
values compared to the non-linear routine (Muskingum-Cunge), but the daily flow generation trend were the same. Only the Muskingum-Cunge results are reported in this paper.

Under ideal circumstances, concurrent observed streamflow data should have been available to evaluate the model capabilities in simulating the flows. Unfortunately, only historical observed data for 19 years (1971-1989) were available and these predate the satellite derived data.. In such circumstance, it could be assumed [8] that long term mean flows have remained unchanged between the two periods and variation due to climate change has not been significant. The daily observed and simulated flows were aggregated to monthly averages across the available years. The model performance was expressed in form of coefficient of determination $\left(\mathrm{R}^{2}\right)$ between the observed and simulated data. The log-transformed values were used so as to take care of both small and large discharges.

The goal of sensitivity analysis is to see if there is any change in model output when the parameter values are modified. The model incorporates a Sensitivity Analysis routine which was used to determine the sensitivity of the twenty (20) parameters in the model. The feasible ranges of the parameters were specified based on the remote sensing datasets and site observations, hence choosing the range was a site-specific process.

\section{Results and discussion}

The estimates from the satellite-derived data adequately reflects (Fig. 3) the monthly variations of the rainfall pattern with peak rainfall occurring in August. However, there is little variation in the magnitude of respective monthly rainfall. This difference can be attributed to the inadequacies inherent in the satelliteobserved computational algorithms and data resolution, as compared to ground observed rainfall [4]. Statistical correlation performed on the data revealed a coefficient of determination $\left(\mathrm{R}^{2}\right)$ of 0.92 indicating a high positive correlation between both datasets (Fig. 4).

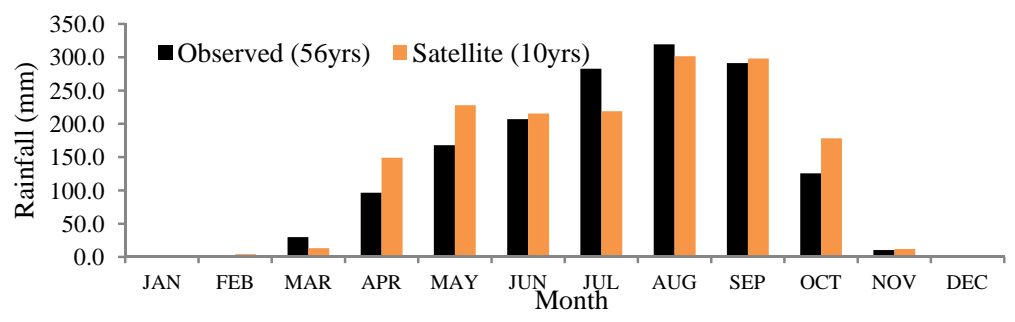

Figure 3: $\quad$ Long-term mean monthly rainfall comparison. 


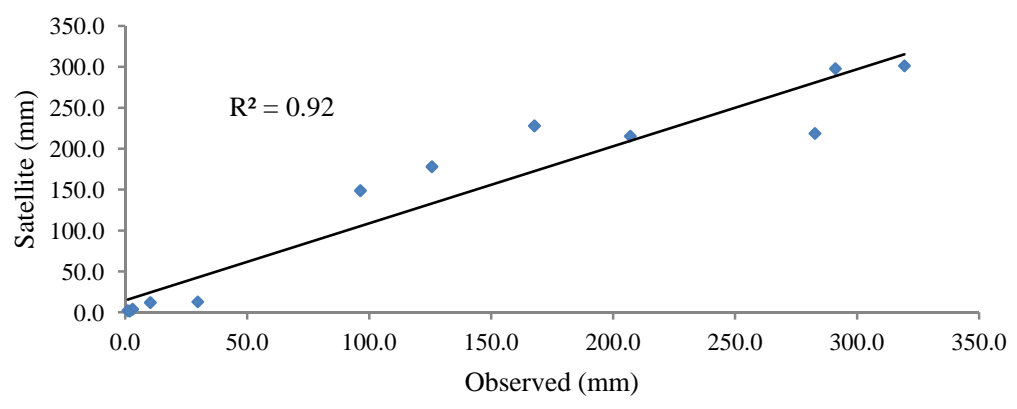

Figure 4: $\quad$ Long-term mean monthly rainfall correlation.

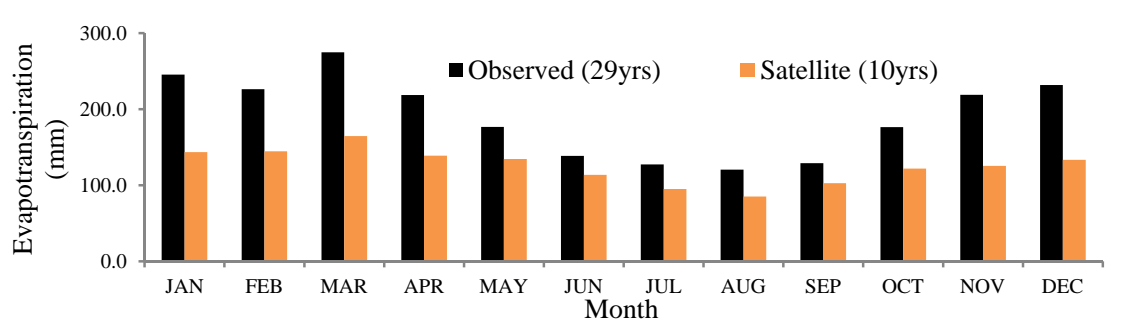

Figure 5: $\quad$ Long-term mean monthly evapotranspiration comparison.

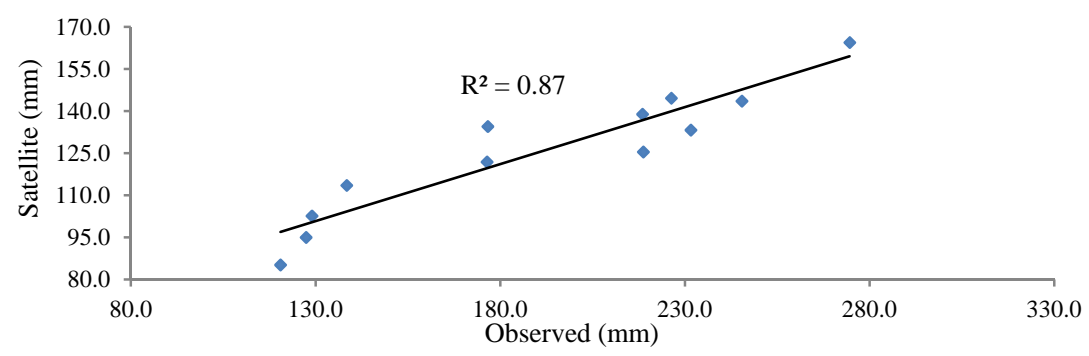

Figure 6: Long-term mean monthly evapotranspiration correlation.

The computed monthly-mean evapotranspiration values from satellite observations adequately capture the seasonal variations in observed values, with maximum evapotranspiration occurring in March and the minimum in August (Fig. 5). The differences in magnitude can be attributed to the data resolution of the satellite estimates and also the method of evapotranspiration computation; the satellite estimates are computed using the FAO Penman-Monteith equation [17], whereas the observed data was computed using the Blaney-Morin-Nigeria equation [18]. Statistical correlation performed on the data revealed a coefficient of determination $\left(\mathrm{R}^{2}\right)$ of 0.87 indicating a high positive correlation between both datasets (Fig. 6). 
Table 1: $\quad$ Parameter sensitivity analysis.

\begin{tabular}{|r|l|l|r|r|}
\hline ID & Description & Name & stddev & Rank \\
\hline 1 & Soil water holding capacity (mm) & SoilWhc & 0.004 & 7 \\
\hline 2 & Total soil depth (cm) & Depth & 0 & 9 \\
\hline 3 & Soil texture: 1=Sand 2=Loam 3=Clay 5=Water & Texture & 0 & 10 \\
\hline 4 & Saturated hydraulic conductivity (cm/hr) & Ks & 0.012 & 4 \\
\hline 5 & Interflow storage residence time (days) & Interflow & 0 & 11 \\
\hline 6 & Average subbasin slope & HSlope & 0 & 12 \\
\hline 7 & Baseflow reservoir residence time (days) & Baseflow & 0.001 & 8 \\
\hline 8 & SCS runoff curve number & CurveNum & 0.015 & 3 \\
\hline 9 & Permanently impervious cover fraction & MaxCover & 0 & 13 \\
\hline 10 & Fraction of soil water to ground water & BasinLoss & 0 & 14 \\
\hline 11 & Pan coefficient for correcting PET readings & PanCoeff & 0.005 & 5 \\
\hline 12 & Fraction of soil layer hydrologically active & TopSoil & 0.005 & 6 \\
\hline 13 & Excess mode 1=NSMA 2=LSMA & RainCalc & 0.042 & 2 \\
\hline 14 & Channel Roughness (Manning n) & RivRough & 0 & 15 \\
\hline 15 & Average slope of the river & RivSlope & 0 & 16 \\
\hline 16 & Average channel width $($ m) & RivWidth & 0 & 17 \\
\hline 17 & Fraction of flow lost within river channel & RivLoss & 0.052 & 1 \\
\hline 18 & Fraction of river flow lost in floodplain & RivFPLoss & 0 & 18 \\
\hline 19 & Flood wave celerity (m/s) & Celerity & 0 & 19 \\
\hline 20 & Flow attenuation coefficient (m^2/s) & Diffusion & 0 & 20 \\
\hline
\end{tabular}

Table 2: $\quad$ Parameter range and optimum value.

\begin{tabular}{|c|c|c|c|c|c|c|c|}
\hline \multirow[b]{2}{*}{ Rank } & \multirow[b]{2}{*}{ ID } & \multirow[b]{2}{*}{ Description } & \multirow[b]{2}{*}{ Name } & \multicolumn{4}{|c|}{ RANGE } \\
\hline & & & & Min & $\begin{array}{c}\text { LSMA } \\
\text { Optimum }\end{array}$ & $\begin{array}{c}\text { NSMA } \\
\text { Optimum }\end{array}$ & Max \\
\hline 1 & 17 & Fraction of flow lost within river channel & RivLoss & 0.01 & 0.7 & 0.26 & 1 \\
\hline 2 & 8 & SCS runoff curve number & CurveNum & 25 & 79 & 86 & 98 \\
\hline 3 & 4 & Saturated hydraulic conductivity $(\mathrm{cm} / \mathrm{hr})$ & Ks & 0.001 & 2.502 & 5 & 12 \\
\hline 4 & 11 & Pan coefficient for correcting PET readings & PanCoeff & 0.6 & 0.85 & 0.85 & 0.95 \\
\hline 5 & 12 & Fraction of soil layer hydrologically active & TopSoil & 0.05 & 0.15 & 0.1 & 1 \\
\hline 6 & 1 & Soil water holding capacity (mm) & SoilWhe & 1 & 165 & 177 & 254 \\
\hline
\end{tabular}

Table 1 lists the model parameters, sensitivity, and ranking based on the standard deviations. Table 2 represents the range of values for most sensitive using the LSMA and NSMA routines. Figures 7 and 8 show that while the general monthly trend (fluctuations) of the simulated flows are close to the observed flow, their magnitudes are different. For both instances of soil moisture accounting, the maximum simulated flows occurred in the month of September and the peak values are well represented, but same cannot be said of the total volume of runoff generated. The LSMA produced a total volume of 2654.42 cubic meters per year, and the NSMA a value of 1631.18 cubic meters per year, as against the observed value of 2132.25 cubic meters per year. In essence, the LSMA over-estimates the observed flows by a ratio of 1.25 , while the NSMA under-estimates the observed flows by a ratio of 0.77 . It can be observed however that the NSMA is better at simulating the shape of the hydrograph although it displays late onset of the rising limb. Figures 9 and 10 show that there is high correlation between the NSMA routine and observed flows despite the tendency to under-estimate the total volume of runoff. The log-transformed coefficients of determination $\left(\mathrm{R}^{2}\right)$ values were 0.68 and 0.96 for both the LSMA and NSMA results respectively. 


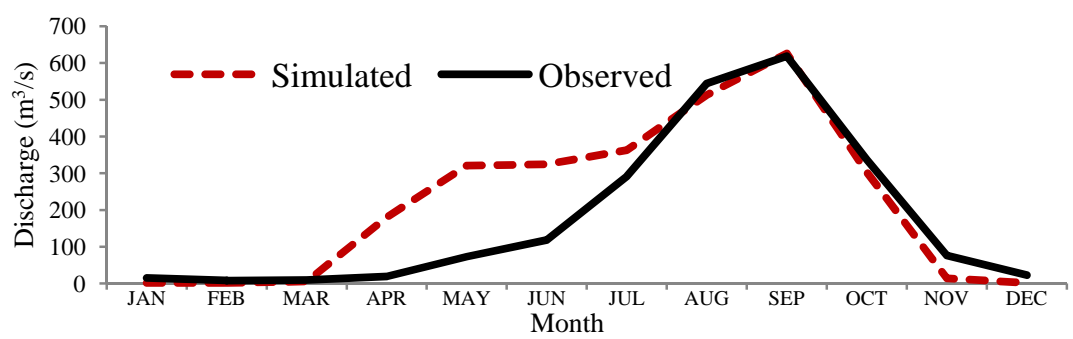

Figure 7: $\quad$ Actual long-term mean monthly flow comparisons (LSMA).

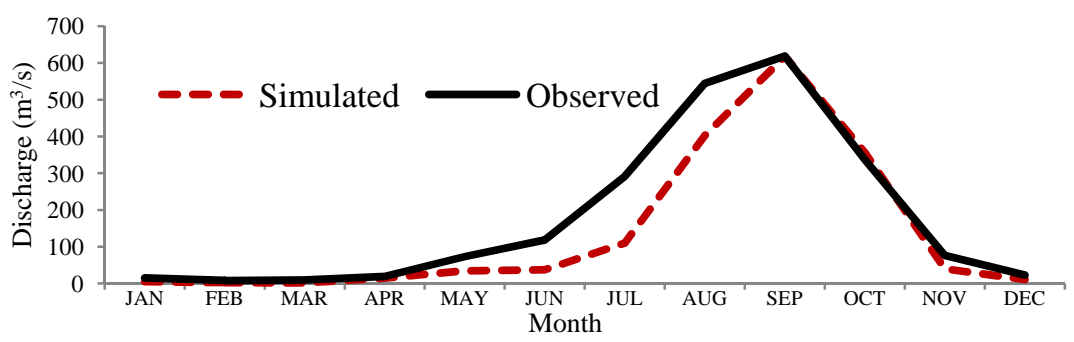

Figure 8: Actual long-term mean monthly flow comparisons (NSMA).

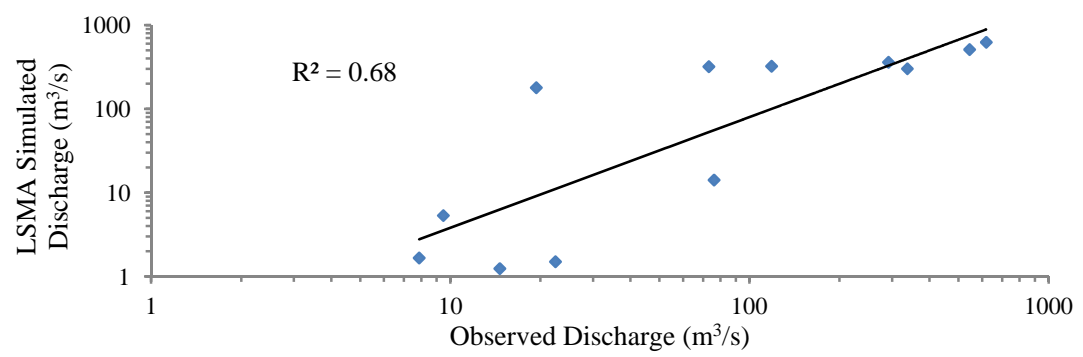

Figure 9: $\quad$ LSMA long-term mean monthly flow correlation.

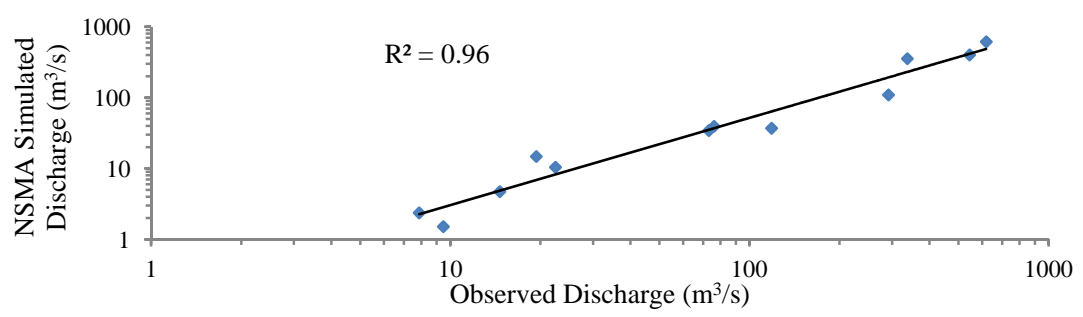

Figure 10: NSMA long-term mean monthly flow correlation. 


\section{Conclusions}

The GeoSFM has 20 parameters but sensitivity analysis showed that the model performance is most sensitive to 6 of the parameters. The fraction of flow lost within the river reach has the highest sensitivity. This confirms that the river channel is above the water table and there is no baseflow contribution to the river flow [3]. Other parameters that affects the performance of the model are the soil moisture accounting procedure, SCS runoff curve number, saturated hydraulic conductivity, pan coefficient for correcting PET, fraction of soil layer hydrologically active and soil water holding capacity. The less sensitive parameters are flood wave celerity and flow attenuation coefficient

The mean monthly rain estimated by the satellite derived data is higher than the observed value during the early and cessation periods of rainy season. The estimated value is lower than observed value during the peak of rainy season. The GeoSFM model using satellite derived data under-estimate observed flow during the early rainy season.

It was found that the GeoSFM model using a satellite derived data could estimate the peak flow from upper Gurara watershed. The model could be used to estimate peak flow in ungauged watersheds in the country. The model was found to be inadequate in estimating the total flow. Soil moisture parameter has a significant effect on simulated streamflow magnitude. The NSMA procedure performs better than the LSMA in determining the soil moisture contribution. Using higher resolution soil characteristics data would improve the flow estimation accuracy [19].

\section{Acknowledgement}

We are grateful to the World Bank funded Science and Technology Post-Basic (STEP-B) project for the Innovators of Tomorrow (IOT) grant that helped achieve this research findings and the presentation of this paper.

\section{References}

[1] Sule, B.F. and Jimoh, O.D., Hydrological regime of the Gurara River. Paper presented at the 5th Annual Conference of National Association of Hydrogeologist; Shiroro Hotel, Minna, 1992.

[2] Jimoh, O.D. and Ayodeji O.S., Impact of the Gurara River Interbasin water transfer scheme on the Kaduna River at the Shiroro Dam, Nigeria. Proc. of Symposium IUGG2003 - Hydrological Risk Management and Development, IAHS Publication, Saporo 281 pp. 277-286, 2003.

[3] Jimoh O.D. and Sule B.F., Hydrological Analysis of Water Balance in the Gurara River Basin Catchment (Nigeria), Proc. of 4th International Conference on Hydraulic Engineering Software. Universidad Politencia, Valencia, Spain pp. 39-49, 1992. 
[4] Artan, G. A., Gadain, H., Smith, J. L., Asante, K, Bandaragoda, C. J., and Verdin, J. P., Adequacy of satellite derived rainfall data for stream flow modeling. Nat Hazards 43 pp. 167-185, 2007.

[5] Asante, K.O., Dezanove, R.M., Artan, G.A., Lietzow, R. and Verdin, J.P., Developing a Flood Monitoring System from Remotely Sensed Data for the Limpopo Basin. Transactions on Geoscience and Remote Sensing, 45(6), pp. 1709-1714, 2007.

[6] Samuels, B. W., and Amstutz E. D., Using HydroSHEDS and GeoSFM to Calculate River Discharge. An International perspective on Environmental and Water Resources. Bangkok, Thailand, 2009.

[7] Asante, K.O., Artan, G.A., Pervez, S., Bandaragoda, C., and Verdin, J.P., Technical Manual for the Geospatial Stream Flow Model (GeoSFM). U.S. Geological Survey Open-File Report, 1441, 2008.

[8] Asante, K. O., Artan, G. A., Pervez, S., and Rowland, J., A linear geospatial stream flow modelling system for data sparse environments. Intl. Journal of River Basin Management 6(3), pp. 233-241, 2008.

[9] Zobler, L., A World Soil File for Global Climate Modelling. National Aeronautics and Space Administration (NASA) Technical Memorandum 87802, 1986.

[10] Webb, S. R., Rosenzweig, C. E., and Levine, E. R,. A Global Data Set of Soil Particle Size Properties. National Aeronautics and Space Administration (NASA), Office of Management Scientific and Technical Information Program, 1991.

[11] Reynolds, C.A., Jackson,T. J., and Rawls, W.J., Estimated Available Water Content from the FAO Soil Map of the World, Global Soil Profile Databases, Pedo-transfer Functions. Data from the USDA Agricultural Research Service. Published by the National Oceanic and Atmospheric Administration (NOAA) National Geophysical Data Center, Boulder, CO, 1999.

[12] United States Geological Survey Global Land Cover Characterization, http://edc2.usgs.gov/glcc/

[13] United States Geological Survey SRTM Project. http://srtm.usgs.gov/

[14] FEWSNET, earlywarning.usgs.gov/fews/africa/web/dwndailyrfe.php.

[15] FEWSNET, http://earlywarning.usgs.gov/fews/global/web/dwnglobalpet. php.

[16] Artan, G. A., Asante, K., Smith, J., Pervez, S., Entenmann, D., Verdin, J., and Rowland, J., User's Manual for the Geospatial Stream Flow Model (GeoSFM). U.S. Geological Survey Open-File Report, 1440, 2008.

[17] Allen, G. R., Luis, S. P., Dirk, R., and Martin, S., Crop evapotranspiration - Guidelines for computing crop water requirements. FAO Irrigation and drainage paper 56, 1998.

[18] Duru, J. O., Blaney-Morin-Nigeria evapotranspiration model. Journal of Hydrology, 70 (1-4), pp. 71-83, 1984.

[19] Meier P., Frömelt A., and Kinzelbach W., Hydrological real-time modelling in the Zambezi river basin using satellite-based soil moisture and rainfall data. Hydrology and Earth System Science 15, pp. 999-1008, 2011. 